\title{
Risk Estimation and Pedigree Analysis
}

\section{C.J. Chapman}

Department of Clinical Genetics, The Churchill, Old Road, Oxford, OX3 7LJ, UK

E-mail: cchapman@hgmp.mrc.ac.uk

For geneticists, an assessment of the likelihood of a particular woman developing breast cancer, given her pedigree, is a necessary but not sufficient prerequisite for the provision of advice about her management.

While a variety of methods of risk assessment have been proposed over the last ten years, based on data from a variety of sources, geneticists should only feel comfortable using methods based on well-validated genetic models. Over the last few years we have used a model based on an analysis of the CASH data-set. Recent information on age-dependent risks associated with mutations in BRCA1 and BRCA2 have confirmed that the model provides a reasonable average estimate of risk for familial breast cancer. Given our genetic model, we use a likelihood-based approach to risk assessment with the LINKAGE package providing these likelihoods for us. Other analytic programs such as MENDEL can be used equally well and in fact provide more flexibility.

These methods are aimed at determining the chance that a woman will develop breast cancer over time, but more recently it has become of interest to ask a slightly different question given the pedigree, what is the likelihood of the DNA laboratory finding a mutation in a particular breast-cancer predisposing gene? One recent program has been developed to provide answers to this question for BRCA1 and BRCA2 BrcaPro. This program and its advantages and limitations will be discussed as will ways in which our own likelihood approach can be adapted to answer the same question. 


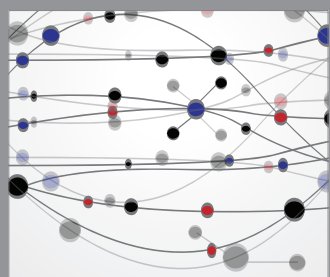

The Scientific World Journal
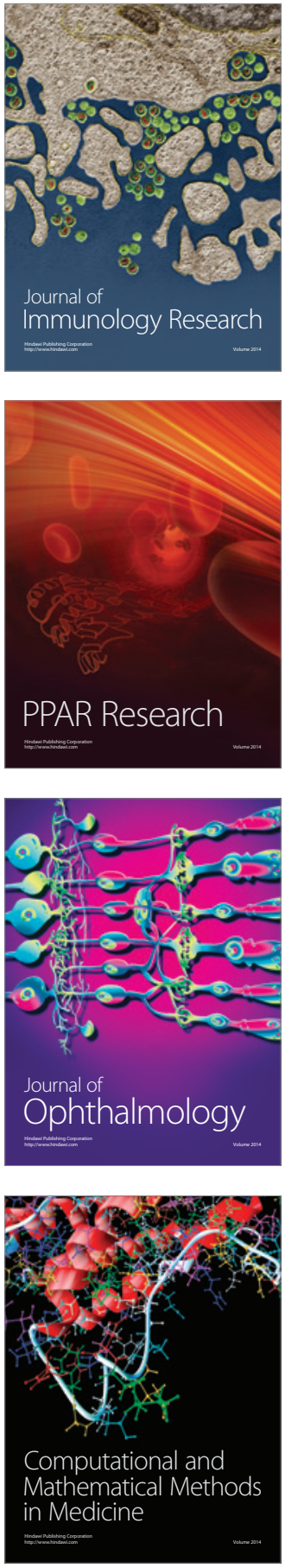

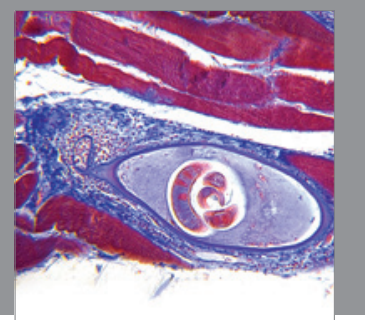

Gastroenterology

Research and Practice
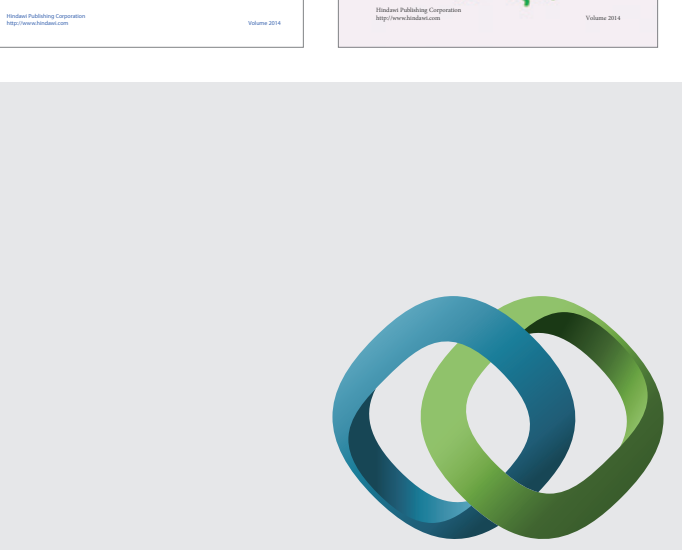

\section{Hindawi}

Submit your manuscripts at

http://www.hindawi.com
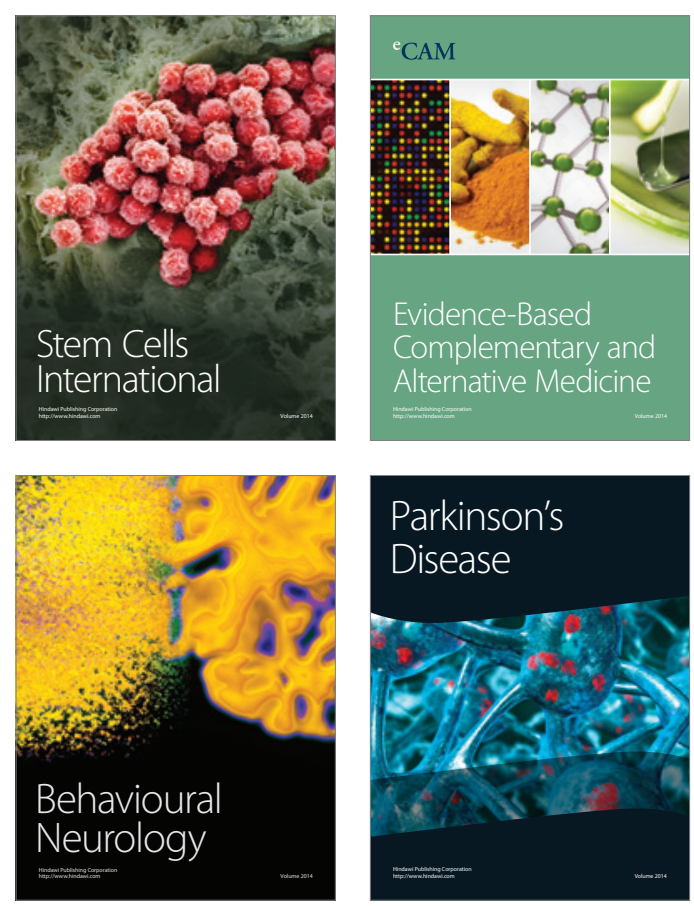

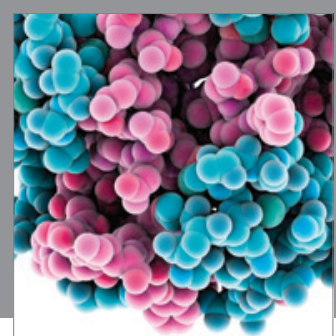

Journal of
Diabetes Research

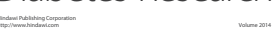

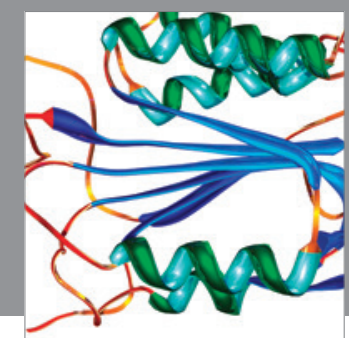

Disease Markers
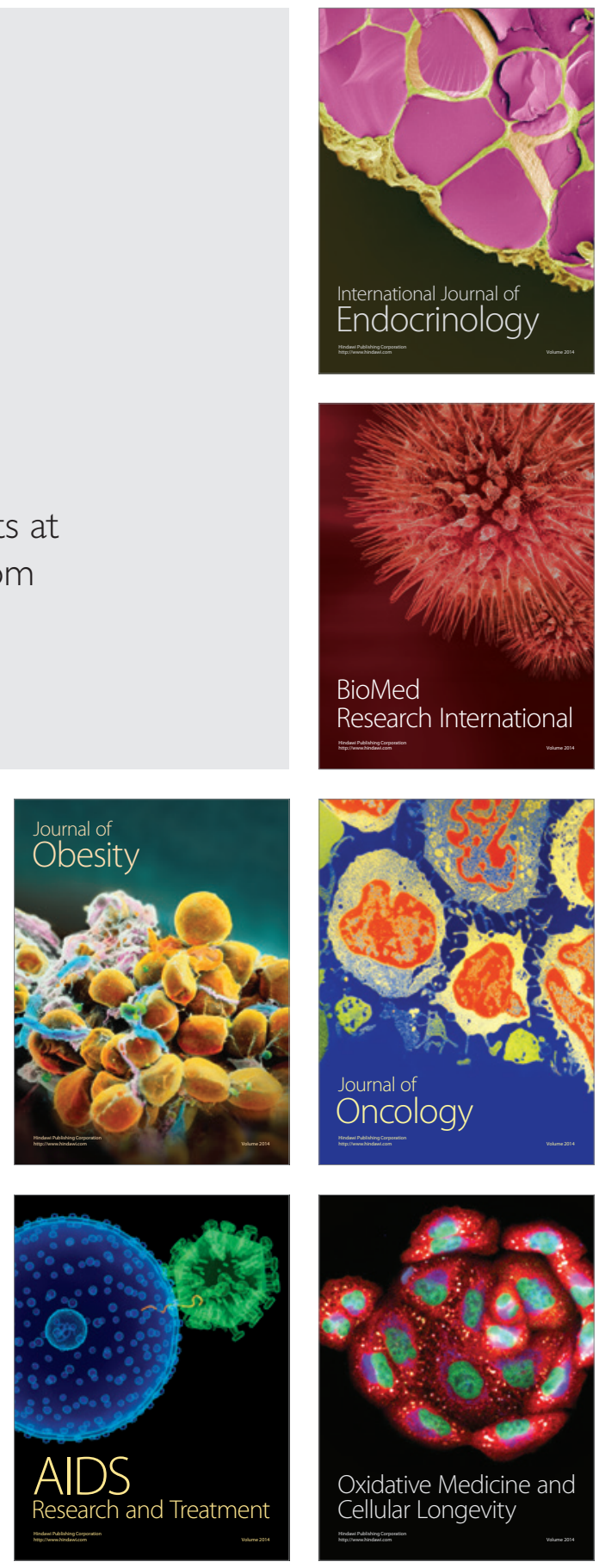